\title{
The Ethics of Speculative Anticipation and the Covid-19 Pandemic
}

\author{
Catherine Kendig ${ }^{1}$ (D) and Wenda K. Bauchspies ${ }^{2}$ \\ ${ }^{1}$ Department of Philosophy, Michigan State University, 368 Farm Lane, 503 South Kedzie Hall, East \\ Lansing, Michigan 48824, USA and ${ }^{2}$ Department of Community Sustainability and Center for Gender in \\ Global Context, Michigan State University, 206 International Center, 427 North Shaw Lane, East Lansing, \\ Michigan 48824, USA \\ Corresponding author. Email: kendig@msu.edu
}

(Received 25 May 2020; revised 19 October 2020; accepted 22 October 2020)

\section{Pandemic Thinking}

The COVID-19 pandemic affects everyone, a statement that is true by definition, yet woefully unhelpful in our understanding of it and its effects today and in the future. Thus we find ourselves in a moment unprepared for the fast-approaching, unanticipated future. ${ }^{1}$ Under stable conditions, we might operate with a "good working model of an anticipated 'future"' to speculate on our preparedness for the possible (Adams, Murphy, and Clarke 2009, 247). Or we may speculate in order to reimagine social relations within new ethical frameworks (Jones 2015). We anticipate what we imagine and envision as possible (Adams, Murphy, and Clarke 2009). We are writing and thinking about this not under stable conditions, but in the early moments of the COVID-19 pandemic when anticipation of and speculation about what is to come is being challenged and contradicted daily in the news cycle by government officials, experts, and everyday citizens. Our thinking, as well as this contribution to the scholarship on the COVID-19 crisis, is defined by an ineluctable tension about what is and what might be. In this musing, we attempt to flesh out just one aspect of the COVID-19 crisis: the anticipatory and speculative nature of COVID-19 thinking. We direct our attention during this time of crisis to how different forms of ethical thinking are joining up, interweaving, and braiding. By framing ethics in the context of anticipation, our aim is to capture threads of anticipation and speculation that may be used to tether attempts to create the future with, after, or beyond the novel coronavirus and/or the next crisis.

SARS-CoV-2 may be a novel coronavirus; fear surrounding the global pandemic may be unprecedented; but the tension between debilitating dread and cautious optimism, reaction and anticipation has itself already been widely discussed. "Scholarship is produced in uneven waves of reaction and anticipation-sometimes prescient about that which has not yet entered the public domain, other times struggling to keep up [with] seismic shifts that render our observations belabored and late" (Stoler 2008, 191). The view of anticipatory ethics in the age of the COVID-19 crisis we outline here builds on earlier scholarship on anticipation in cultural anthropology by Ann

(c) The Author(s), 2021. Published by Cambridge University Press on behalf of Hypatia, a Nonprofit Corporation. This is an Open Access article, distributed under the terms of the Creative Commons Attribution licence (http://creative commons.org/licenses/by/4.0/), which permits unrestricted re-use, distribution, and reproduction in any medium, provided the original work is properly cited. 
Laura Stoler; research on the gendered impact of anticipation in technoscience by Vincanne Adams, Michelle Murphy and Adele Clarke; and the recent research on speculative fiction by Esther Jones (Stoler 2008; Adams, Murphy, and Clarke 2009; Jones 2015).

\section{What is Speculative Anticipation?}

What should we do? How should we behave? How much do we really need? Who should be responsible? Who should work? Who should stay home? How do we flatten the curve? How does the "we" that we speak from affect our answers to these questions? ${ }^{2}$ Ethical questions have been part of the COVID-19 pandemic conversation and our interactions in discussions over: hoarding toilet paper and baking yeast; the impact on those holding jobs deemed to be essential (for example, nurses, nurses' aides, grocery store clerks, primary care givers); the growing recognition that these may be held predominantly by women and especially by women of color whose responsibilities may also include responsibilities for home-schooling children and care of older parents; ensuring that the various stay home, stay safe, save lives injunctions to protect medical workers are maintained; and making sure that provisions for ethical quarantine in prisons and detention centers are secured.

We were used to asking these ethical questions around inequality and who benefits and who is harmed prior to SARS-CoV-2. What the COVID-19 crisis has made different is the heightened visibility of these ethical considerations around who is protected and who is unprotected and how their protection from and vulnerability to disease often depends on systemic social, economic, and political structures of society. As a society we are in the process of identifying where and in what ways we can think through our interactions with one another and the environment in light of the uncertainty of COVID-19 in public and private spaces. ${ }^{3,4}$ Our aim is to fill a gap in the current public discourse: to provide an analysis of what ethics looks like in the space of speculative anticipation.

At the moment, we find ourselves inside the COVID-19 pandemic searching for old and new ethical pathways to move us into the future that we want to imagine. Anticipation has been defined in many ways. Adams, Murphy, and Clarke argue that anticipation is the "one defining quality of our current moment"; it is the state of affairs of "thinking and living toward the future" (Adams, Murphy, and Clarke 2009, 246). An anticipatory state of affairs focuses on a perceived imminent reality that may not become actualized. This is a situation that generates possible worlds as possible speculative futures. These futures are not logical spaces of possibility, but instead define a moral space of possibility where what one conceives of as possible in the future influences the choices made in the present. This is a possibility space where the "future sets the conditions of possibility for action in the present" (249). In this way, anticipation is the possibility space where the future has already happened: the pandemic; the global death toll; social distancing; distribution of the vaccine; and decisions and actions affecting the workforce, economy, global climate change, and systemic racism have already happened. This type of temporal foreshortening of modal space is what Adams, Murphy, and Clarke call "the telescoping of temporal possibilities" (249). For Jones, anticipation is not merely the domain of logical or ethical expressions, but also of selfshaping fictional possibilities:

Speculative fiction encompasses the genres of science fiction, fantasy, horror and related forms within a kind of "super-genre" that interrogates an empirical reality 
we presume we know through the strategies of discontinuity, change and difference.... [T] he speculative [is used to] identify historical patterns, amplify contemporary social and political problems and envision futures in which alternative approaches to justice may be imagined. (Jones 2015, 4-5)

Braiding together these different concepts of anticipation, we can see that anticipation has epistemic, ethical, and social value. It also provides the means by which to explore new sites of anticipation in ways that may reconfigure what is possible. The risk is that it inflicts demands to always "stay informed!" that themselves can bring unequal harm to those whose lives are put in a perpetual state of both unknowing and alertness. As Adams, Murphy, and Clarke write:

Anticipation is not only an epistemic orientation toward the future, it is also a moral imperative, a will to anticipate. ... [T] here is a moral injunction to anticipate as an act in which life, death, identity, and prosperity are at stake personally and collectively. Anticipation calls for a heralding of the emergent "almost" as an ethicized state of being. Being ready for, being poised awaiting the predicted inevitable keeps one in a perpetual ethicized state of imperfect knowing that must always be attended to, modified, updated. The obligation to "stay informed" about possible futures has become mandatory for good citizenship and morality, engendering alertness and vigilance. (Adams, Murphy, and Clarke 2009, 254)

These different concepts of anticipation provide a necessary perspective from which to make future decisions as well as to craft current policies. ${ }^{5}$ These may affect social gatherings for years to come and may themselves have ethical impacts we are only now beginning to fathom. They also beget the feeling of impending inevitability and uncertainty about what is to come as we anticipate what might be the result for future gatherings of families, friends, and colleagues. But along with ethical consideration of these decisions and policies, we argue that anticipation itself ushers in a novel set of ethical considerations along with the virus that has global, local, and future responses.

\section{Speculative Anticipation as an Exploratory Stage of Moral Thinking}

We focus on speculative anticipation to highlight the exploratory stage of moral thinking that comes with-as well as prior to-anticipation. It is the set of activities that takes place when either the signs are simply insufficient to read, are unreliable, conflicting, or do not afford what might-in non-pandemic times-be considered reasonable bases for action. We ask these questions, framed by speculative anticipation, in the hope of fueling and supporting analysis and structure that may be overlooked, silenced, or ignored. We hope that doing so will be useful in navigating the spaces of ethical and social discourses (especially those around inequity) that SARS-CoV-2 has highlighted and continues to highlight.

Cities have become efficient spaces to house, feed, and entertain high numbers of residents. Under the threat of SARS-CoV-2, they have shifted to become COVID-19 hotspots. ${ }^{6}$ This gives rise to the fear of using mass transit and the daily challenges of wage-workers to pay rent and care for their families. SARS-CoV-2 has raised many ethical questions for cities: why is the mortality of black and brown occupants from COVID-19 higher than that of white occupants? Is it ethical for those with means to leave the city and become temporary residents of remote places without the infrastructure to accommodate them? If socioeconomically disadvantaged individuals and 
families suffer from severe sickness with COVID-19 more frequently than those who are wealthy, how can we provide less confined living and working environments and better health care to increase equity?

New questions of speculative anticipation quickly follow from these ethical questions: how do we build affordable housing in wealthy neighborhoods to increase equal access to education, decrease commute times, and extend life expectancy for all residents after COVID-19? What opportunities can we create from the current COVID-19 failures to improve and stabilize society through increased health care, wages, food supply, and economic stability? What might be the future implications of the COVID-19 crisis on agriculture and agriculture supply chains and markets? How can we use our knowledge of COVID-19 crises to mitigate the risks to local and global food systems post-COVID?

Writing in the midst of the first year of the COVID-19 pandemic, we offer a schematic to help lay the groundwork for actual planning for what might be a postpandemic reality. We leave to others with expertise in epidemiology, public health, sociology, and economics the analysis of the global impact; the best measures; evaluations of the particular modes of decision-making relied upon for policy and predictions about the spread of the virus; and assessments of how things have changed in light of the pandemic. Instead, we discuss and evaluate a particular form of ethical reasoning that seems to typify current COVID-19 pandemic thinking: that is, a mode of ethical consideration focused on figuring out how to best anticipate in unruly times. Thus, we focus on braiding together the global, local, and projective speculative forms of anticipation ethics in this constantly shifting, liminal, and complex of social challenges precipitated by SARS-CoV-2.

\section{Three Ontological-Epistemological-Ethical Spaces of Speculative Anticipation}

Many conversations are engaging in speculation and anticipation during this pandemic. News media, social media, and academic dialogues seem to be consumed by what is possible and what might be possible. What is not dominating the social discourse are the ways that ethics is being understood and is becoming shaped by the pandemic; whose ethics are shaping the response to the crisis; consideration of what ethics are available; how to respond; and which clusters of ethical and social considerations should we attend to first as we move through the stages of the crisis and beyond. Our inquiry began by asking: What does it mean to think about ethics in light of SARS-CoV-2? This in turn led to an exploration of what we called an "ethics of speculative anticipation." Our own speculative anticipation identified three potential sites of speculative anticipation; there may, of course, be others. In the next section, we describe these three different sites of speculative anticipation. Following these descriptions, we provide a short explanation of how these ontological-ethical spaces of speculative anticipation can interweave and braid together.

\section{Global Speculative Anticipation}

Global speculative anticipation focuses on what might be the ethical considerations and decision-making to think about when one reflects on international or worldwide spaces that we find ourselves in and how to think about our possibilities within it in a global way. For instance, questions might be: What world do we want to live in? How do we plan for it, for example, to increase equity and sustainability? What are the ethical ways 
to consider and problematize our way in the world to strive toward these goals? Global speculation may lead us to ask whether there is something similar about the predicted futures that arise in the present crisis to those of the past? For instance, we may ask: How do we provide and maintain access to clean water? How should we attend to food systems and global supply chains to address food insecurity and the management of food production? How might we best evaluate international trade and tourist routes and hubs? Or how can we ensure increased global and open access to data and research? By not asking these questions, we risk our COVID-19 pandemic approach not being as novel as the virus that caused it. Focusing on the anticipatory nature of speculation during pandemics, especially as it pertains to food-production and supply chains, is imperative if we want to avoid the mistakes of the past and ensure food and regional security:

Food production is not only governed through a century-old speculative logic of commodity "futures," it has also become a problem space for the control of anticipated epidemics ... connecting the FAO to the CDC to the WHO, creating new territorial linkages between Asia, Africa, and North America. (Adams, Murphy, and Clarke 2009, 251)

One of many promising ways to begin thinking about global speculative anticipation is by revisiting research that highlights how the lives of communities and nations are affected differently based on the "racialized relations of allocations and appropriations" embedded in our current global social, political, and economic infrastructures (Stoler 2008, 193). The question before us is: will we use these same racialized policies, gendered relations, and values to respond and create the post-COVID-19 future?

\section{Local Speculative Anticipation}

Local speculative anticipation focuses on considering one's own situatedness and seeking to understand the situatedness of other people who are not in similar situations within the pandemic. Consideration of local situatedness as others experience it is required for local speculative anticipation. Speculation without this is simply selfreflection, which is rarely useful to others differently situated. Within this space, we might also consider opportunities to consciously think about the COVID situation of others and the nature of this space of opportunities for us, for example, how might ethical decisions be considered while being careful not to assume that there is an obligation on the part of some (especially those suffering from institutional injustices) to fix things? What sort of ethical thinking is needed for consciously exploring the opportunities in living with SARS-CoV-2? Considering the ethical impacts requires understanding our own vantage point, how we rely on others and how they rely on us through a web of dependencies. Knowledge of our interconnectedness isn't enough. We know the pandemic affects us all and we are all connected. But this knowledge is useless unless we consider what this means and how we can act:

While we may all ultimately be connected to one another, the specificity and proximity of connections matter-who we are bound up with and in what ways. Life and death happen inside these relationships. And so we have to understand how particular human communities, as well as those of other living beings, are entangled. (van Dooren 2016, 60) 
Several particularly acute examples show how the pandemic has affected people's lives differently. During the pandemic the normal boundaries and limits employed by essential care workers have been disrupted. Professional responsibilities have left many essential care workers with the choice between taking care of their family and taking care of their work. Families that are food insecure must make decisions about who is fed and who is not (for example, children, primary workers, sick family members). In addition to food insecurity, sanitary-supply needs of women and girls may get overlooked or sacrificed by family decision-makers in times of crisis.

Families may also be exposed to increased vulnerability to gender-based violence that can negatively affect children, women, and men. This means that local anticipation means action in some cases such that we "prepare for increases in gender-based violence, including domestic violence, intimate-partner violence and sexual exploitation and abuse" (World Food Programme 2020). The differential impact of the increased demands and risks on those working in health care, care work, farming, and food service and how these increased stressors affect populations differently in terms of their socioeconomic status represent only a small sample of spaces where local speculative anticipation facilitates ethical decision-making.

\section{Projective Speculative Anticipation}

Projective speculative anticipation focuses on what life will be like beyond the pandemic. In particular, what will our ethical and social framework look like on the other side? How will COVID-19 be understood afterwards, for example, will it be endemic, like smallpox or polio, or will it be like malaria, where different areas of the world and different populations are affected worse than others or during certain seasons or within different climates? Whichever way it manifests in the future, how will we deal with, redefine, or attempt to resolve issues around inequality and inequity with all of these potential scenarios? For instance, projective speculative anticipation may involve provisioning that is aimed to mitigate the risks of both the current pandemic but also to coordinate policies that improve food security and nutrition and address climate change while building resilience within local and global communities. Solutions may take international efforts and employ joined-up policies, for instance, projective speculation may mean that:

Policy makers must monitor trends and take care to avoid accidentally tightening food-supply conditions ... as well as building the resilience of food chains to avoid similar occurrences in the future. New technologies could facilitate the interface between supply and demand, which would be of great value to highly perishable goods (like fruit and vegetables...). (Food and Agriculture Organization of the United Nations 2020)

Within these three ontological-epistemological-ethical spaces of speculative anticipation are overlapping forms of moral epistemology. The knowledge of possibilities that is generated as well as the understanding of how progress should be made toward these possibilities and by whom inflect each one. These possibility-led, ethical, goal-oriented approaches to anticipation may guide how we think about the future, attempt to plan in situations of uncertainty, and frame the ethical questions that we see arise in our immediate and global contexts. 


\section{Limits to Speculative Anticipation}

In the previous section, we separated out 1) global, 2) local, and 3) projective speculative anticipation in order to explore different areas of anticipation and to investigate how and within what networks of relationships they aligned. The three distinctions ask slightly different questions from slightly different perspectives, enabling us to broaden the discussion of ethics and speculative anticipation. However, we do not see these as discrete, unconnected categories.

One's global space shapes one's local spaces and the possibility spaces one perceives as near or far. It is this relationship between here and there that fuels anticipation. One's local speculative anticipation is not picked from a selection of individual options, but instead is framed in terms of the immediate networks of individuals (neighbors, friends, community, family, and so on) as well as one's global neighbors, international allies, multi-country unions, diasporas, and homelands. Anticipation is always done by individuals or communities in dialogue. This can happen even when the two individuals in dialogue are oneself at time T1 and one's projected self at time T2.

The space one occupies now inflects how one conceives of global, local, and projective speculation. It is a space that may enable or restrict one's abilities to speculatively anticipate in ways that differentially affect those in different spaces. In the SARS-CoV-2 situation, it is not just those one is quarantining with, but the work environment and local contexts that afford and impinge on one's ability to speculate about what might happen in the future (of self, family, friends, colleagues, and community). One's situatedness might be conceived of in a way that could afford or frustrate the possibility of self-projecting and community-projecting speculation. Jones describes this possibility space as one that can be furnished by speculative fiction:

Speculative fiction is one place where black women can be portrayed as selfactualized and strategies for survival are expressed. It is where radical forms of medical and social justice are imagined... while writing new prescriptions for how to relate humanely and ethically across differences.... In other words, the imaginings born out of historical truths and political realities can ultimately move us to manufacture a potentially new kind of relationship and existence and to plot a map for survival and transcendence. This is the task which speculative genres perform so well. (Jones 2015, 6)

The possibility space (and the self-actualization) that Jones speaks of here is one of optimism, a place where one acts freely as author of her own future. Charting and navigating this space of speculative fiction "bring[s] a fresh approach to destabilize hegemonic ideologies and practices in their efforts to imagine new ethical relations" (12). Through the lens of SARS-CoV-2, we may also view this possibility space as one that is experienced not as one that furnishes optimism, but also fear and pessimism. Understanding how local and global speculative spaces are inhabited differently by different people, communities, and decision-makers also requires understanding how and in what ways different people anticipate differently from others in the same local and global frames.

\section{Actively and Responsibly Envisioning New Futures}

The goal of this musing was to explore the role of speculative anticipation in ethics during the COVID-19 pandemic in order to provide a structure for thinking about ethical 
decision-making in times of extreme uncertainty. We did this by focusing on the speculative nature of anticipation; anticipatory activities; ethical decision-making in worldwide and local contexts; and what the future might look like with regard to the ongoing pandemic. In doing so, we have outlined how global, local, and projective speculative anticipation offer a way to situate ourselves in the space of possibilities as a guide to what may become actual. Stated in a far less abstract way, thinking of what might and could be in the future opens up the possibility to plan a careful and thoughtful route from quarantine to social distancing from a situated perspective that braids together broader social issues such as food security, health care, and environmental issues with individual and national security. ${ }^{7}$

Global, local, and projective anticipation as outlined above aim to define three different domains within which speculative anticipation is found. These frames may, on their own, be discussed in ways that bring opportunity or limitations. As such, they might be judged as being positive or negative-for the individual, the community, the society, or for the future. We hope our discussion, building on the work of Stoler, Jones, Adams, Murphy, and Clarke, has shown the ability of these conceptions to be actualized from people's own situated standpoint within which they experience the pandemic and how their own local and global situatedness differentially affects how they might anticipate and potentially plan their lives and consider their future.

The impacts of one's local and global situatedness collectively contour the spaces for speculative anticipation. They often shape what is possible, where it is possible, and how it is possible to explore the complex realities of the lived social world. Our analysis here aims to open possibilities for seeing the situatedness of others to address larger social issues laid bare by the presence of SARS-CoV-2. This is "an opportunity to recast our questions, to revisit assumptions, to embrace ... the more uncomfortable" (Stoler 2008, 192). Our account of the different forms of ethical speculative anticipation is intended to be useful. We offer it as a tool to "recast our questions" and "revisit assumptions" in the context of the COVID-19 pandemic (and what it highlights). By using the frame of speculative anticipation, we are seeking ways to consider how new futures could be reconceived that vitiate rather than systematically reproduce inequity, and instead actively and responsibly envision those futures that are informed by equity and sustainability.

\section{Notes}

1 The unanticipated future is coming to us with a velocity that highlights the lag between when we wrote this in the beginning months of the COVID-19 pandemic in the US to its publication date and opens the possibility that our readers may be reading this after we may have surpassed a global death toll of 1.5 million people.

2 What we mean here is that these questions are both posed and answered within the ethical and social ecologies of communities. Where we are speaking matters not only in terms of our geographical position but within which frameworks we are speaking. The ineluctable indexicality of the "we" that we use to label ourselves within our communities means that our knowledge is, as Donna Haraway has discussed, always "situated" (Haraway 1988). As such, the situatedness of knowledges always affects what is afforded as well as what is obscured.

3 This is an environment that permits and encourages race-targeted violence, oppression, exploitation, police brutality, and systemic racism. It erases the work of black and brown men and women and silences marginalized voices in order to benefit those in power. The COVID-19 pandemic has shone a light on some of these and further obscured others. What it has provided in some spaces is a vision that racial injustice isn't just in one place at one time but in our own communities. COVID-19, like racial injustice, is everywhere and so requires collective thinking. COVID-19 amplifies inequities and exacerbates the ongoing 
violence to black and brown people at the hands of authoritative racialized systems. This exacerbation has made it more widely visible to policymakers and their communities.

4 This article also builds on early discussions about uncertainty in the context of epidemiology, especially with regard to the transmission of SARS-CoV-2 by experts in epidemiology and public health and the philosophy thereof (Cabrera 2020; Valles 2020).

5 Current polices include: stay-at-home orders, masks in public places, social distancing of six feet or two meters between individuals, testing, contact-tracing, quarantine, and frequent handwashing.

6 This has meant the necessity of closing well-loved iconic institutions: schools, museums, theaters, restaurants, markets, barber shops, and parks.

7 We did not intend the examples we chose, focusing largely on agricultural and food systems, to represent all possible ethical considerations within the current crisis. Working at a land grant university with specific interests in agriculture, biotechnology, and inequity meant these were most closely aligned to our own areas of research and familiarity.

\section{References}

Adams, Vincanne, Michelle Murphy, and Adele Clarke. 2009. Anticipation: Technoscience, life, affect, temporality. Subjectivity 28: 246-65.

Cabrera, Laura. 2020. The promises and perils of using collective data to monitor COVID-19. Bioethics in the News. Center for Ethics and Humanities in the Life Sciences. Michigan State University. https://msubioethics.com/2020/04/23/promises-and-perils-of-using-collective-data-to-monitor-covid-19-cabrera/.

Food and Agriculture Association of the United Nations. 2020. COVID-19 pandemic: Impact on food and agriculture. http://www.fao.org/2019-ncov/q-and-a/impact-on-food-and-agriculture/en/.

Haraway, Donna. 1988. Situated knowledges: The science question in feminism and the privilege of partial perspective. Feminist Studies 14 (3): 575-99.

Jones, Esther. 2015. Medicine and ethics in black women's speculative fiction. New York: Palgrave Macmillan.

Stoler, Ann Laura. 2008. Imperial debris: Reflections on ruins and ruination. Cultural Anthropology 23 (2): 191-219.

Valles, Sean. 2020. Episode 68-Sean Valles. Sci Phi Podcasts. Interviewed by Nick Zautra. March 18. http:// www.sciphipod.com/podcast/2020/3/18/episode-68-sean-valles.

Van Dooren, Thom. 2016. Flight ways: Life and loss at the edge of extinction. New York: Columbia University Press.

World Food Programme. 2020. Gender and COVID-19. https://www.wfp.org/publications/gender-andcovid-19.

Catherine Kendig is an Associate Professor in the Department of Philosophy at Michigan State University. Her research focuses on the normative and metaphysical commitments that underpin formal and informal classification systems. She has published widely on the epistemic value and potential problematic uses of natural kinds and classification. Kendig serves as associate editor of the journal History and Philosophy of the Life Sciences, and co-editor of the series History of Philosophy and Science (De Gruyter). She is editor of the collection of interdisciplinary essays Natural Kinds and Classification in Scientific Practice (Routledge, 2016). (Email: kendig@msu.edu)

Wenda K. Bauchspies is an Associate Professor of Community Sustainability at Michigan State University and Co-Director of the Center for Gender in Global Context. She is an interdisciplinary and international social scientist whose expertise lies in the integration of gender, social justice, and culture with agricultural research, science education, and technological adaptation. Her research has been published in a variety of journals such as FACETS, Subjectivity, Social Epistemology, and Journal of Asian and African Studies, and she is a co-author of Science, Technology and Society: A Sociological Approach. (Email: bauchspi@msu.edu)

Cite this article: Kendig C, Bauchspies WK (2021). The Ethics of Speculative Anticipation and the Covid-19 Pandemic. Hypatia 36, 228-236. https://doi.org/10.1017/hyp.2020.56 